\title{
Programa de produção mais limpa no setor de panificação da cidade de Marabá-PA
}

Luciana Barbosa de Miranda miranda.lubarde@gmail.com Universidade Estadual do Pará (UEPA), Marabá, Pará, Brasi

Johnnathan Santana Franco johnnathan_franco@hotmail.com Universidade Estadual do Pará (UEPA), Marabá, Pará, Brasi

Glauber Epifânio Loureiro prof.glauber.uepa@gmail.com

Universidade Estadual do Pará (UEPA) Marabá, Pará, Brasil

\author{
RESUMO
}

As atividades industriais demoraram décadas para inserir a variável ambiental em suas decisões, no entanto recentemente tem surgido iniciativas sustentáveis no processo produtivo de grandes e pequenas empresas. Um desses setores é a indústria de panificação, que apesar de ser um ramo de pequeno porte e que não gera resíduos perigosos, isso não impede que sejam aplicadas novas tecnologias sustentáveis de produção. Uma dessas tecnologias é a Produção Mais Limpa $(\mathrm{P}+\mathrm{L})$, que visa otimizar o processo produtivo e prevenir a geração de resíduos. Tem objetivo de elaborar um programa de $(\mathrm{P}+\mathrm{L})$ no setor de panificação da cidade de Marabá-PA. A pesquisa é de caráter indutiva, exploratória e descritiva, além de ser um estudo de caso caracterizado como qualitativo. Utilizou-se a metodologia de $\mathrm{P}+\mathrm{L}$ proposta pelo Centro Nacional de Tecnologias Limpas (CNTL) e pela Agência de Proteção Nacional dos EUA (EPA). Obteve-se que a principal medida a ser proposta foi a utilização da massa de pré-mistura, juntamente com a adoção da pré-pesagem e de recipientes para dosagens, além da segregação e comercialização dos resíduos da panificadora. Tais propostas, tem baixo investimento e promovem o aumento da produtividade, diminuição dos custos de produção e a redução da geração de resíduos.
\end{abstract}

PALAVRAS-CHAVE: Panificação. Produção mais limpa. Resíduos. 


\section{INTRODUÇÃO}

Nos primórdios da atividade industrial a variável ambiental não era integrada as decisões da empresa, no que se refere ao seu processo produtivo, ao consumo de matéria prima e a disposição final dos resíduos. Assim, conforme Werner, Bacarji e Hall (2011), "durante décadas o processo de degradação ambiental cresceu vertiginosamente, acreditando-se que o crescimento econômico proporcionaria melhores condições de vida para a sociedade". No entanto, ao longo de alguns anos, percebe-se que a melhoria da qualidade de vida não se deve apenas ao crescimento econômico, mas sim em práticas sustentáveis de tal crescimento. De maneira que o meio ambiente seja visto como alicerce, sendo inserido às decisões da empresa.

Para Fernandes e Freitas (2014), "a massificação dos problemas ambientais vivida pela sociedade moderna é um indicador da crise do atual modelo de desenvolvimento que tem contribuído para o consumo desenfreado dos recursos naturais e a degradação dos mesmos".

Dentre as principais atividades industrias que consomem os recursos naturais e que vem sendo alvo de estudos ambientais, tem-se o setor da panificação, que segundo Junior et al., (2012), "as padarias estão deixando de serem apenas estabelecimentos responsáveis pela fabricação artesanal e venda de pães, Estes estabelecimentos passaram a serem chamados de panificadoras e confeitarias, por estarem se transformando em centros de conveniência, gastronomia e serviços".

De acordo com o levantamento realizado pelo Instituto Tecnológico de Panificação e Confeitaria (ITPC) em parceria com a Associação Brasileira da Indústria de Panificação e Confeitaria (ABIP), no brasil existem 63,2 mil empresas que compõem o setor. Em 2015 as empresas do segmento de Panificação e Confeitaria brasileiras registraram um crescimento de $2,7 \%$, com o faturamento chegando a R\$ 84,7 bilhões (ABIP, 2016).

Já na cidade de Marabá, das 161 panificadoras registradas no cadastro municipal, 92 tem como atividade econômica a fabricação de produtos de padaria e confeitaria com predominância na produção própria (SEGFAZ, 2016). Porém, nem todas elas possuem uma estrutura física de boa qualidade, acarretando em desperdícios de matéria prima e disposição inadequada dos resíduos.

A partir disso, surge então a preocupação com a poluição ambiental causado por este setor, que apesar de ser uma indústria com resíduos de característica não perigoso, isto não deve ser motivo para que as panificadoras não adquiram práticas sustentáveis de produção. Logo, a indústria da panificação tem-se demonstrado ser um causador de problemas ambientais por dois motivos, o primeiro refere-se a carência do gerenciamento adequado dos resíduos sólidos, já o segundo, para Fernandes e Freitas (2014), "são problemas basicamente relacionados com a eficiência produtiva que leva a um maior consumo de matérias primas e energia e consequente geração de desperdícios e resíduos".

Diante desde último problema abordado, busca-se inserir dentro do setor de panificação uma gestão que utilize novas tecnologias de produção que visem a prevenção a poluição, que segundo a NBR ISO 14001:2015 "pode incluir redução ou eliminação da fonte; modificações no processo, produto ou serviço". Assim, entre as metodologias de prevenção a poluição tem-se a Produção Mais Limpa $(\mathrm{P}+\mathrm{L})$, cuja metodologia propõe aplicação continuada de uma estratégia ambiental preventiva e integrada aos processos e produtos, a fim de aumentar a eficiência, reduzir os riscos a sociedade e ao meio ambiente, visando ganhos de 
competitividade e a otimização dos processos industriais (WERNER; BACARJ; HALL, 2011). Esta metodologia tem como princípio básico eliminar a poluição ainda no processo produtivo, e não após o mesmo (PEREIRA; SANT'ANNA, 2012).

Assim, a implementação da estratégia da $\mathrm{P}+\mathrm{L}$ exige que todo o processo produtivo seja avaliado, verificando sua real eficiência quanto ao emprego de recursos e energia. Essa avaliação está baseada na realização de um balanço de massas e energia e na identificação das medidas para $\mathrm{P}+\mathrm{L}$, que sejam as mais apropriadas (MILLAN; GRAZZIOTION, 2011). Com o intuito de englobar mudanças nos produtos e nos seus processos de produção a fim de reduzir ou eliminar os rejeitos deles criados (FINGER; NETO, 2010).

Com isso a $\mathrm{P}+\mathrm{L}$ promoverá a construção de um ambiente favorável para a mudança organizacional, uma vez que fomenta a criação de um grupo direcionado para o mesmo objetivo e de forma estruturada, estimula todos a refletir, analisar, avaliar as possíveis soluções e a compartilhar do mesmo sentimento de mudança (BERTÉLI; BARCELLOS; CARVALHO, 2013).

Portando, o presente artigo tem como objetivo, elaborar um programa de $\mathrm{P}+\mathrm{L}$ no setor de panificação da cidade de Marabá - PA.

\section{METODOLOGIA}

A presente pesquisa é definida como de caráter indutivo, exploratória e descritiva. Quanto a abordagem do problema e aos procedimentos técnicos, para o primeiro caracteriza-se como sendo qualitativa e o segundo como estudo de caso e pesquisa bibliográfica. Para a execução das coletas de dados, foi feito uma entrevista com a proprietário do empreendimento utilizando um formulário, além da observação sistemática. O período de coleta de dados foi de 30 dias, não corridos, correspondendo aos meses de dezembro de 2016, janeiro e fevereiro de 2017.

No que se refere ao método de abordagem, a indução é um processo mental por intermédio do qual, partindo de dados particulares, suficientemente constatados, infere-se uma verdade geral ou universal, não contida nas partes examinadas. Portanto, o objetivo dos argumentos indutivos é levar a conclusões cujo conteúdo é muito amplo do que das premissas nas quais se basearam (MARCONI; LAKATOS, 2010).

Quanto aos objetivos da pesquisa, as pesquisas exploratórias têm como objetivo proporcionar maior familiaridade com o problema, com vistas a torná-lo mais explícito ou a constituir hipóteses. Já a descritiva, têm como objetivo primordial a descrição das características de determinada população ou fenômeno, ou então, o estabelecimento de relações entre variáveis (GIL, 2010).

Os aspectos destes dos dois tipos de pesquisa citados acima, estão presentes neste estudo, pois, busca-se obter um maior entendimento acerca da aplicação da metodologia $\mathrm{P}+\mathrm{L}$, e também descrever o processo produtivo e os aspectos ambientais da panificadora.

No que consta a abordagem do problema, a pesquisa qualitativa tem como uma de suas características: a objetivação do fenômeno; a hierarquização das ações de descrever, compreender e explicar; respeito ao caráter interativo entre os objetivos buscados pelos investigadores, suas orientações teóricas e seus dados empíricos (GERHARDT; SILVEIRA, 2009). Já quanto aos procedimentos técnicos, o estudo de caso consiste no estudo profundo e exaustivo de um ou poucos objetos, de maneira que permita seu amplo e detalhado conhecimento 
(GIL, 2010).

A pesquisa bibliográfica foi realizada a partir do registro disponível, decorrente de pesquisas anteriores, em documentos impressos, como livros e manuais, e em links eletrônicos, como os periódicos (SEVERINO, 2007).

$\mathrm{Na}$ realização das visitas técnicas a empresa, um dos instrumentos de pesquisa utilizado no momento da entrevista foi o formulário, no qual consiste em um roteiro de perguntas enunciadas pelo entrevistador e preenchidas por ele com as respostas do pesquisado (MARCONI; LAKATOS, 2011).

Já quanto a técnica de observação sistemática, para Marconi e Lakatos (2010), "o observador sabe o que procura e o que carece de importância em determinada situação. Deve ser objetivo, reconhecer possíveis erros e eliminar sua influência sobre o que vê ou recolhe".

Sobre as etapas para a elaboração deste programa, utilizou-se como referência a metodologia de $\mathrm{P}+\mathrm{L}$, proposta pela $\mathrm{CNTL}$, Centro Nacional de Tecnologias Limpas (2003) e pela EPA, Agência de Proteção Ambiental dos EUA (1992). Portanto o presente programa seguiu as seguintes etapas (Figura 1):

Figura 1- Etapas do programa de prevenção a poluição

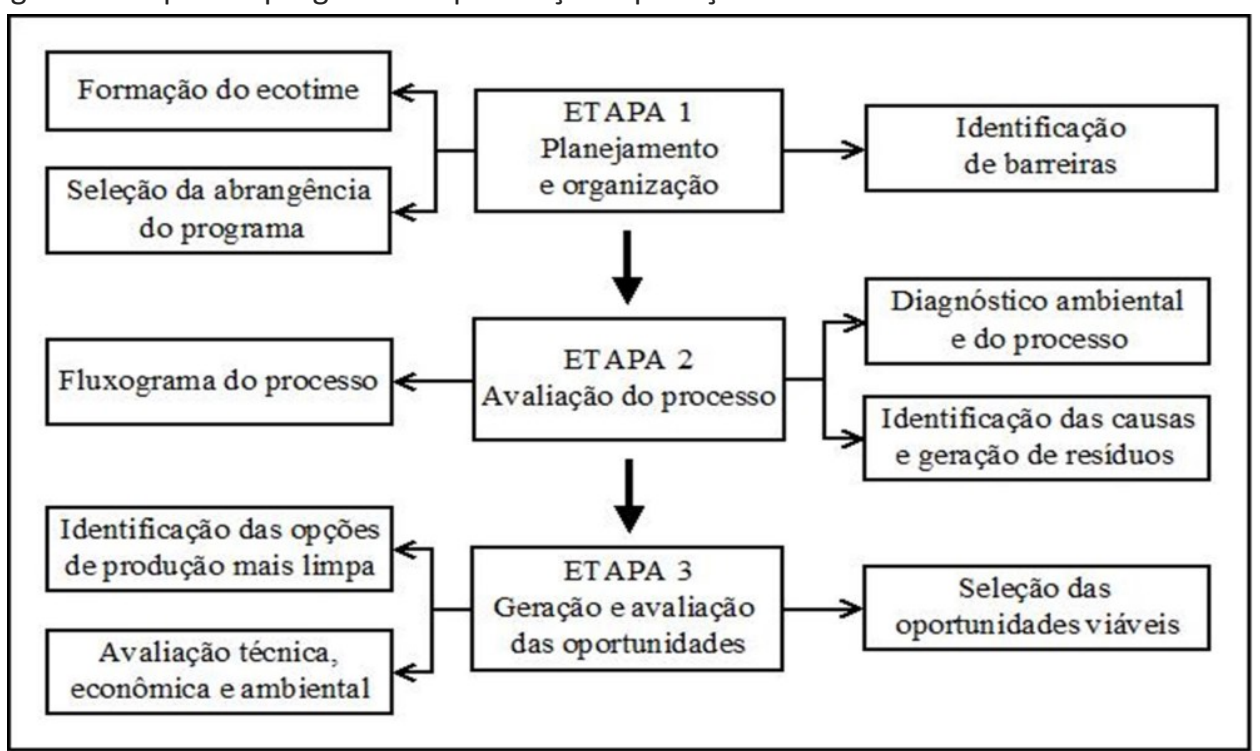

Fonte: CNTL (2003) e EPA (1992).

Na Etapa 1 - planejamento e organização, ocorreu o planejamento para a formação do ecotime, no qual consiste em grupo de trabalho formado por profissionais da empresa que tem por objetivo conduzir o programa de $\mathrm{P}+\mathrm{L}$ (CNTL, 2003). Além disso, foi definido a abrangência desta ferramenta na empresa, selecionando produtos a fim de delimitar o problema. Também, objetivando o bom funcionamento do programa, a identificação de barreiras buscou identificar e prever soluções para os problemas que possam vir a ocorrer durante o desenvolvimento do programa, e na sua aplicação, caso ele seja implantado.

Já a Etapa 2 - avaliação do processo, consistiu na coleta de dados e sua posterior interpretação. Assim, foi realizado visitas técnicas na empresa, com o intuito de conhecer o funcionamento dos setores que a compõem. A partir disso, ocorreu a criação e descrição do fluxograma do processo produtivo, além do diagnostico ambiental e do processo, no qual refere-se a quantificação das entradas (insumos) e saídas (resíduos). Ainda tem-se a identificação das causas da geração de resíduos e dos fatores que dão origem aos resíduos na empresa. 
Na Etapa 3 - geração e avaliação das oportunidades de $P+L$, foram identificados as opções de $P+L$ aplicáveis a panificadora, logo foi feito a avaliação técnica, econômica e ambiental de cada uma das opções e em seguida ocorrerá a seleção das medidas viáveis para a empresa.

\section{RESULTADOS E DISCUSSÃO}

\section{CARACTERIZAÇÃO GERAL DA EMPRESA}

A panificadora em estudo está localizada na cidade de Marabá- PA, estando há 23 anos em funcionamento. É uma empresa legalizada, emprega 10 funcionários e que contém as atividades de confeitaria e produção própria. Funciona todos os dias da semana. De segunda-feira até o sábado, o horário de funcionamento corresponde de $6 \mathrm{~h}$ às $10 \mathrm{~h} 30$ e de $14 \mathrm{~h}$ às $20 \mathrm{~h}$. Porém no domingo o expediente abre as $6 \mathrm{~h}$ e fecha às $12 \mathrm{~h}$. Sobre o número de funcionários por setor, 2 ficam no setor de produção de pães, 1 na confeitaria, 4 no balcão de atendimento, 2 no caixa e 1 no auxílio de serviços gerais.

\section{FORMAÇÃO DO ECOTIME}

Para o melhor desempenho do programa, casa seja aplicado, será indicado a formação de uma equipe de funcionários da empresa, juntamente com os profissionais responsáveis pela elaboração deste programa. Assim, visando manter uma equipe que contenha integrantes de diferentes setores da empresa, propõe-se realizar uma reunião com todos os funcionários, objetivando disseminar aos funcionários a importância da $\mathrm{P}+\mathrm{L}$ e selecionar dois deles para integrar o ecotime. Eles terão as funções de monitorar e dar continuidade as medidas de $\mathrm{P}+\mathrm{L}$, além de localizar, registar e solucionar qualquer eventual desperdício no setor produtivo.

\section{SELEÇÃO E ABRANGÊNCIA DO PROGRAMA}

Após a pesquisa bibliográfica e o levantamento de informações gerais com o proprietário, notou-se que apesar do ideal ser a análise de toda a linha de produção, verificou-se a inviabilidade da aplicação da $\mathrm{P}+\mathrm{L}$ em todo o processo produtivo da panificadora, devido suas complexidades, pois seria preciso uma avaliação extensa na qual demandaria vários meses de medições e pesquisa. Além disso, a empresa seria resistente a ceder todas as informações necessárias.

Assim, visando realizar um estudo viável e detalhado para determinados produtos, foi feito um recorte e analisou-se somente a produção do pão francês e o pão doce, conhecido na região como pão de sal e pão massa fina respectivamente, pois são os produtos com maior oferta e demanda na panificadora em estudo.

\section{IDENTIFICAÇÃO DAS BARREIRAS}

Apesar da implementação da $\mathrm{P}+\mathrm{L}$ trazer benefícios econômicos e 
ambientais a empresa, é comum existir barreiras a sua aplicação. A panificadora em estudo não é diferente, pois no decorrer das visitas técnicas realizadas na empresa, surgiram situações que dificultaram o levantamento de informações. Assim, para a elaboração do presente programa foram encontradas as seguintes barreiras:

- Dificuldade para realizações das medições devido a estrutura no setor de produção e a passagem constante de funcionários no referido local.

- Constrangimento dos funcionários ao serem observados. Isso influenciou na maneira como eles exerciam suas funções, pois tentavam causar uma boa impressão.

- Ausência de informações quanto os dados de produção mensal.

Além disso, existem barreiras que possam vir a acorrer, caso o programa seja implementado na empresa, entre elas tem-se a limitação da estrutura organizacional e restrição de recursos financeiros para aplicação das medidas de $\mathrm{P}+\mathrm{L}$, por isso é necessário o estudo da viabilidade econômica, técnica e ambiental das oportunidades de $\mathrm{P}+\mathrm{L}$, para evitar a existência destas barreiras, já que os estudos citados acima auxiliam na escolha de medidas que estejam dentro da disponibilidade dos recursos da panificadora.

Outras barreiras que poderão ser encontradas são: resistência a mudanças, advinda tanto dos funcionários quanto do próprio proprietário; indiferença dos funcionários quanto medidas de $\mathrm{P}+\mathrm{L}$ adotadas e ausência de comprometimento do ecotime. Como solução propõe-se a realização de uma palestra abordando os benefícios da produção mais limpa além de reuniões constantes com a equipe do ecotime.

\section{DIAGNÓSTICO AMBIENTALE DO PROCESSO}

Primeiramente, no que consta a recepção e armazenamento de matériasprimas, a panificadora, contém duas portas de entradas, uma para os clientes e outra para os funcionários. Esta última é anexa a área de produção, sendo utilizada também para a recepção de matérias-primas, de onde seguem para o estoque principal. No entanto, para facilitar o trabalho dos funcionários, parte dos insumos utilizados na produção do pão francês e do pão doce são armazenados em um compartimento abaixo do balcão de produção e em uma bancada ao lado, porém não há uma quantidade regular de matéria prima estocada nestes locais.

No que consta os horários de produção, o pão francês é produzido de segunda-feira a sábado, às $10 \mathrm{~h}$ da manhã e às $16 \mathrm{~h}$ da tarde, e no domingo apenas no horário das 10 h. Já o pão doce é produzido às $7 \mathrm{~h}$, todos os dias da semana. Já quanto as etapas do processo produtivo, a produção do pão francês e do pão doce são praticamente as mesmas, tendo como diferença apenas algumas matérias-primas e tempo de realização das etapas. Com isso, optou-se por descrever o processo de fabricação do pão francês e a elaboração do seu fluxograma juntamente com o do pão doce. O processo é dividido em seis partes no qual serão descritas a seguir.

Seleção e pesagem: de acordo com o tipo de pão a ser produzido os ingredientes são pesados em uma balança eletrônica, utilizando sacos de rafia para armazenar temporariamente a farinha de trigo a ser medida. A pasta, manteiga e a bisnaga são colocados em um copo plástico. Já para o sal, açúcar e o fermento, utiliza-se a tampa dos recipientes destes ingredientes para a medição. $\mathrm{E}$ por último a água gelada, com o auxílio de um balde, é medida a gosto pelo 
padeiro.

Mistura: com o intuito de homogeneizar os ingredientes, os componentes são misturados em uma amassadeira industrial obedecendo um ordem de acordo com o tipo de produto. $O$ ponto da mistura ideal é obtido pelo tempo de batida, pelo aspecto visual da massa e, principalmente, pelo tato do profissional ao abrir um pedaço da massa (SENAI, 2007).

Divisão: para a execução desta etapa, primeiramente para que a massa não se adere ao balcão, este recebe uma camada de óleo de cozinha, com o auxílio de um pincel. A massa então é cortada manualmente com um faca e pesada seguindo um peso padrão de para os dois tipos de pão estudados. Então a massa é dividida em um equipamento modelador de uso manual, denominado divisora, obtendo-se uma massa fracionada em 30 unidades de pão a cada divisão.

Modelagem: tem a finalidade de proporcionar o formato final dos pães, por meio da inserção uma a uma da massa fracionada em um dos lados da máquina modeladora. Então os pães saem modelados do outro lado da máquina.

Fermentação: nesta etapa os pães são colocados em bandejas no qual são postas em câmaras de crescimento, objetivando que a massa tenha um período de descanso para fermentar e crescer. Vale ressaltar que antes de seguir para a próxima etapa, apenas o pão francês recebe o chamado risco ou corte, com o intuito de deixa-lo com o seu design tradicional.

Forneamento: os pães são assados em forno elétrico industrial, por um período de 15 minutos, o pão francês à uma temperatura de 170 ㅇ e o doce à 150․ Vale destacar que o forno possui 11 câmeras de queima e possui um dispositivo sonoro que avisa o termino da assadura.

A Figura 2 apresenta o fluxograma do processo para a produção de 468 pães franceses e 378 pães doces, estes valores equivalem a uma unidade de produção para ambos os pães. Para o pão francês, no período da manhã ocorrem quatro unidades de produção e quatro no período da tarde. Já o pão doce é feito apenas uma unidade no período manhã. Vale ressaltar que após a etapa de mistura do pão doce, são retirados $5 \mathrm{~kg}$ de massa misturada destinado para a produção de pães encomendados, no qual não será abordado no presente estudo. 
Figura 2 - Fluxograma do processo produtivo do pão francês e do pão doce

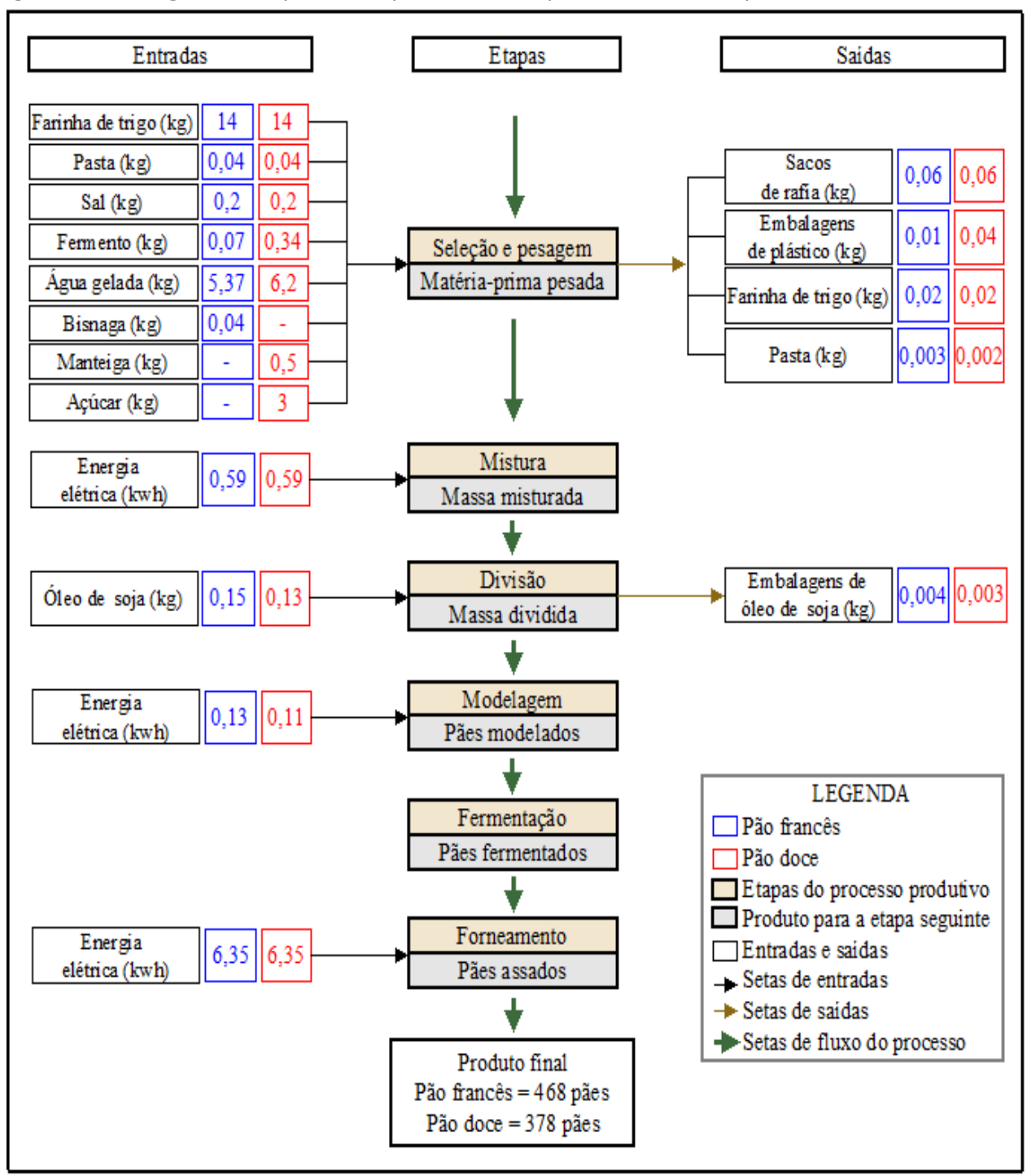

Fonte: Autoria própria (2017).

A partir da Figura 2, foi estimado um consumo de energia elétrica na produção do pão francês de 7,07 kwh com um custo de $\mathrm{R} \$$ 4,00 e de 7,05 kwh para o pão doce, também com um custo de $R \$ 3,99$. Assim, levando-se em consideração as unidades de produção e os dias produzidos em um mês, estimase um custo de $\mathrm{R} \$ 999,25$ com a energia elétrica na produção do dois tipos de pães estudados. Apesar desse valor, não foi identificado desperdício no consumo de energia elétrica. Já em relação a água, não há custo para o seu consumo, pois a água consumida no processo é proveniente de um poço freático da própria panificadora. Já quanto ao isumos, considerando a Figura 2, elaborou-se o Quadro 1 , na qual demonstra o custo dos insumos para a produção dos pães. 
Quadro 1 - Custo dos insumos para a produção de 468 pães franceses e 378 pães doces

\begin{tabular}{|c|c|c|c|c|c|c|c|c|}
\hline Insumos & $\begin{array}{c}\text { Farinha } \\
\text { de trigo }\end{array}$ & Pasta & Sal & Fermento & Bisnaga & Manteiga & Açúcar & $\begin{array}{c}\text { Óleo de } \\
\text { soja }\end{array}$ \\
\hline $\begin{array}{c}\text { Custo } \\
\text { para o } \\
\text { pão } \\
\text { francês } \\
\text { (R\$̦) }\end{array}$ & 25,48 & 0,88 & 0,14 & 0,84 & 0,8 & - & - & 0,57 \\
\hline $\begin{array}{c}\text { Custo } \\
\text { para o } \\
\text { pão } \\
\text { doce } \\
\text { (R\$) }\end{array}$ & 25,48 & 0,88 & 0,14 & 4,08 & - & 2,25 & 4,5 & 0,49 \\
\hline
\end{tabular}

Fonte: Autoria própria (2017).

Com isso, obteve-se um preço dos insumos para o pão francês de $R \$ 28,71$ e $\mathrm{R} \$ 37,82$ do pão doce. Por mês se teria então um valor estimado de $\mathrm{R} \$ \mathbf{6 . 3 1 6 , 2 0}$ e $\mathrm{R} \$ 1.134,60$ respectivamente. Portanto, considerando a energia elétrica, mensalmente estima-se um custo de $\mathrm{R} \$ \mathbf{8 . 4 5 0 , 0 5}$ para a produção desses pães. Vale ressaltar que no cálculo, não considerou-se a mão de obra empregada.

\section{IDENTIFICAÇ̃̃O DAS CAUSAS E GERAÇ̃̃O DE RESÍDUOS}

A partir do fluxograma do processo produtivo, foi evidenciado uma perda de farinha de trigo e de pasta na etapa de Seleção e Pesagem. Para ambos os pães houve uma média de desperdício de $0,02 \mathrm{~kg}$ de farinha de trigo. Para o pão francês, isso resultaria em torno de $4,4 \mathrm{~kg} / \mathrm{mês}$, com um custo mensal estimado de $R \$ 8,06$. Já o pão doce, esses valores seriam mais baixos, com um desperdício de cerca de $0,6 \mathrm{~kg} / \mathrm{mês}$, e um custo de $\mathrm{R} \$ 1,09$. Esta perda de matéria-prima ocorre devido o recipiente aonde o trigo é pesado, na qual são utilizados embalagens da própria farinha de trigo, que são os sacos de rafia, assim na inserção do trigo na amassadeira, parte do conteúdo desperdiçado fica ainda no saco e outra parte é lançado para fora da amassadeira devido ao manuseio incorreto.

Já em relação a pasta, há uma perda de 0,003 kg e 0,002 kg para o pão francês e pão doce, respectivamente, devido à má raspagem do conteúdo da embalagem. Assim, estima-se uma perda mensal de 0,66 kg e um custo de $\mathrm{R} \$$ 14,52 para o pão francês, em que haveria um perda anual de $\mathrm{R} \$ 174,24$. Já para o pão doce, o desperdício mensal seria de $0,72 \mathrm{~kg}$ com um valor de $\mathrm{R} \$ 15,84$.

Quanto a mensuração da água utilizada no processo, verificou-se que há um certa discrepância na utilização da água, resultando na perda de matéria prima, pois não há uma dosagem padrão, sendo utilizada em média 5,37 kg de água para o pão francês e 6,2 kg para o pão doce.

No que se refere aos resíduos de embalagens de plástico e de rafia, levando em consideração todas as unidades de produção do pão francês e doce feitas, mensalmente são gerados cerca de 20,52 kg. Verificou-se ainda que alguns sacos de rafia são reutilizados para as dosagens do trigo, como já foi mencionado anteriormente, no entanto, ao final estes sacos juntamente com as embalagens de plástico são armazenados temporariamente de maneira inadequada, sendo colocados em um pequeno deposito, um local escuro, com pouca circulação de ar, 
causando odores e atraindo alguns animais sinantrópicos, como baratas, formigas e moscas. Ao final, estes resíduos são transportados pela prefeitura, para o aterro controlado do município.

\section{IDENTIFICAÇÃO DAS OPÇÕES DE PRODUÇÃO MAIS LIMPA}

Com base no diagnostico obtido, foi possível sugerir mudanças no processo produtivo, a fim de diminuir a geração de resíduos e otimizar o processo. Em que por meio da avaliação técnica economia e ambiental foi possível selecionar as medidas de $\mathrm{P}+\mathrm{L}$ viáveis a empresa.

\section{Utilização da Farinha de Pré Mistura}

A pré-mistura é um grande agente de inovação nas padarias. Ela agiliza e auxilia o processo de padronização, também reduz o tempo de fabricação e eleva produtividade na indústria. Estudos do ITPC comprovam que algumas receitas produzidas com pré-mistura obtiveram aumento na produtividade de até $34 \%$ se comparadas com a fabricação de receitas tradicionais (OLIVEIRA; RODRIGUES; ALVES, 2012).

Além disso, a substituição da farinha de trigo pela massa de pré-mistura é um procedimento simples, que irá envolver principalmente os dois padeiros responsáveis pelo setor de produção. Ainda, o processo produtivo mudará, devido a não ter mais a necessidade de pesar todos os ingredientes descritos na figura 2, pois a massa já contém a farinha de trigo, a pasta, o sal, a bisnaga, a manteiga e o açúcar, onde será necessário manipular somente a massa de pré-mistura, o fermento e a água, resultando apenas na pesagem destes três ingredientes.

Ainda, como a massa de pré-mistura já contém parte dos ingredientes, ocorrerá uma diminuição em torno de $90 \%$ dos resíduos de embalagens de plástico na etapa de Seleção e Pesagem, pois os resíduos irão se restringir apenas as embalagem do fermento e da farinha de trigo.

Quanto aos resíduos de sacos de rafia, este não será gerado devido a embalagem da pré mistura a ser proposta possuir embalagem diferenciada em papel kraft reciclável. Este papel é produzido por meio da junção de fibras de celulose curtas e longas, além de possuir uma boa resistência mecânica, em que devido ao formato quadriculado da embalagem, facilitará o armazenamento por empilhamento, resultando no melhor aproveitamento do espaço destinado ao armazenamento dos insumos. Além disso, os sacos de papel kraft podem ser reciclados mais facilmente se comparado com os sacos de rafia, pois o papel kraft é utilizado para a fabricação o papelão ondulado. Já os sacos de rafia são geralmente reutilizados, no entanto, são poucas as cooperativas que compram este material usado.

Atualmente há uma custo $\mathrm{R} \$ 25,48$ em farinha de trigo por unidade de produção, isso resulta em uma despesa mensal em torno de $\mathrm{R} \$ 6.370,00$. Já com a utilização da massa de pré-mistura em torno de $R \$ \$$ 6.856,30. Percebe-se que haverá uma estimativa de aumento de cerca de $\mathrm{R} \$ \mathbf{4 8 6 , 3 0}$. No entanto apesar desse aumento, haverá uma redução na compra de matéria prima, pois a utilização da massa de pré-mistura requer apenas a compra do fermento. Assim, excluindo os valores com energia elétrica, na produção atual, o custo mensal é em

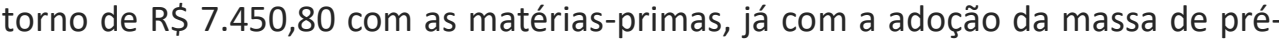


mistura seriam cerca de $\mathrm{R} \$ \mathbf{7 . 1 6 3 , 5 0}$

Assim, como demonstra Fernandes e Freitas (2014), na utilização da massa de pré-mistura "os ganhos econômicos seriam sentidos tanto através da diminuição do tempo de fabricação e das perdas de matéria-prima durante a pesagem individual de cada ingrediente, reduzindo assim o custo de produção e aumentando a produtividade da padaria".

\section{Pré-pesagem}

Na etapa de Seleção e Pesagem, recomenda-se pesar as matérias-primas em quantidade suficiente para uma semana. Para o sal, o fermento e o açúcar propõe-se coloca-los em recipientes de plástico, já a pasta, bisnaga, manteiga e o óleo, ficariam em seus próprios recipiente de fábrica, fazendo apenas uma estimativa de quantos pacotes seriam usados em uma semana. Todos estes ficariam armazenados abaixo do balcão de pesagem para facilitar sua manipulação. No entanto, para a farinha de trigo e a água não seria aplicado este método, devido ao trigo ser utilizado em maior quantidade e necessidade da água ser mantida no freezer, a fim de mantê-la gelada.

Assim, será necessário aquisição de recipientes para o armazenamento de algumas matérias primas pré-pesadas. Para isso, haverá um custo de cerca de R\$ 26,00 .

A pré-pesagem evitaria o desperdício no manuseio das matérias primas, e consequentemente aumentaria o desempenho dos padeiros, pois os ingredientes ficariam mais próximos da bancada de produção.

\section{Manuseio Adequado da Matéria-prima}

Para o melhor aproveitamento do conteúdo da pasta e do trigo, propõese com o auxílio de uma colher, uma melhor raspagem do conteúdo da embalagem da pasta. E também a verificação do conteúdo do saco de rafia. Isso evitará o desperdício mensal em torno de $1,38 \mathrm{~kg}$ de pasta e $5 \mathrm{~kg}$ de trigo. Esta é uma medida que não terá nenhum investimento econômico, no entanto irá exigir um pouco mais de atenção dos dois padeiros presentes no setor de produção.

\section{Recipientes para Dosagens}

Propõe-se a aquisição 5 recipientes, no qual serão feitas demarcações das dosagens padrões com o intuito de aumentar a produtividade e consequentemente evitar o desperdício de matéria- prima. Para isso será necessário um investimento de $R \$ 30,00$. Assim como as outras medidas de $\mathrm{P}+\mathrm{L}$, está também irá exigir atenção dos pandeiros, para que utilizem o recipiente correspondente para cada matéria prima.

\section{Segregação e Comercialização Dos Resíduos Sólidos}

No estudo de Junior et al., (2012) os resíduos das panificadoras "também poderiam serem comercializados e não somente descartados. Esta prática traria ótimas contribuições para o meio ambiente por ser $\mathrm{P}+\mathrm{L}$, onde aborda-se a 
reciclagem externa trazendo ganhos".

Assim, propõe-se que os resíduos sejam dispostos em dois coletores, um para as embalagens de plástico e outro para as embalagens da farinha de trigo, sejam eles de sacos de rafia ou de papel kraft. Os recipientes serão dispostos próximo do setor de produção, a fim de facilitar a manipulação. Para isso, será necessário um investimento de $\mathrm{R} \$ 180,00$ para a compra dos coletores. Está medida ainda irá exigir ações de educação ambiental para que os funcionários sejam participativos e tenham consciência da correta segregação.

Ainda, após a segregação destes resíduos, será feita sua comercialização para uma empresa local. A Panificadora em estudo terá que disponibilizar um funcionário para ficar responsável pelo transporte destes resíduos até a empresa que os compram.

A comercialização dos resíduos irá gerar um renda mensal de $\mathrm{R} \$ 30,00$ considerando o método de produção atual, no qual utilizam as matérias-primas dispostas na Figura 2. No entanto, caso uma das alternativas a serem selecionadas seja o uso da massa de pré-mistura em que utilizam os sacos de rafia como embalagens, haverá uma renda mensal de $R \$ \$$ 6,84. Já caso as embalagens das massas de pré-mistura sejam de papel kraft, terá então uma arrecadação de $\mathrm{R} \$$ 5,44 por mês.

Os valores bem baixos com a venda destes resíduos demonstram que a panificadora em estudo não apresenta grande geração de resíduos, se atendo apenas as embalagens das matérias- primas utilizadas. Além disso, por meio do gerenciamento destes resíduos, haverá um redução de $100 \%$ dos resíduos de embalagens de plástico da panificadora dispostos no aterro controlado do município de Marabá, garantindo assim uma boa visibilidade para a empresa para os seus clientes, no que se refere a sua relação com meio ambiente.

Contudo, como os valores arrecadados com a venda dos resíduos são muito baixos, e pode não fazer diferença no lucro total da empresa. Tem-se outra opção, no qual estes resíduos sejam doados, com a exigência de que a cooperativa na qual se destina o material, busque as embalagens na panificadora.

\section{SELEÇÃO DAS OPORTUNIDADES VIAVEIS}

A partir da avaliação técnica, econômica e ambiental, observou-se que a utilização da massa pré-mistura apresentou ser a medida mais viável, pois além de diminuir cerca de $90 \%$ da geração de resíduos de embalagens de plástico, também terá um economia estimada de $\mathrm{R} \$ 287,30$ por mês. Outra medida seria a prépesagem e a utilização de recipientes para dosagens, no qual terá seu investimento financeiro reduzido para $R \$ 8,00$ e $R \$ 11,00$, respectivamente, devido a adoção da massa de pré-mistura, que reduz a quantidade de insumos na produção. Onde também haverá influência na Segregação e Comercialização dos Resíduos Sólidos, pois como já foi mencionado haverá redução na geração destes materiais. Como a arrecadação com a venda terá um valor insignificante para a empresa, cerca de $\mathrm{R} \$ 5,44$. Os resíduos seriam doados para um empresa de reciclagem.

Ainda, para que não se repita o desperdício de matéria-prima, ressalta-se o Manuseio Adequado da Matéria-prima, quanto a etapa de Seleção e Pesagem da massa de pré-mistura. Uma medida simples, que não requer investimento financeiro, mas somente a atenção dos funcionários no ambiente de produção.

Praticamente as medidas propostas terá investimento zero, pois como a 
empresa já terá uma economia de $\mathrm{R} \$ \mathbf{2 8 7 , 3 0}$ por mês. Em que serão retirados deste valor um investimento de $\mathrm{R} \$ 199,00$ para a compra das lixeiras e dos recipientes para dosagens e pré-pesagem. No entanto, ainda haverá uma economia de R\$ 88,30 no primeiro mês. Onde, a partir do segundo mês, é estimado uma economia de $\mathrm{R} \$ 287,30$.

\section{CONCLUSÃO}

Para este trabalho a metodologia de $\mathrm{P}+\mathrm{L}$ trouxe benefícios financeiros $\mathrm{e}$ ambientais, com o intuito identificar as oportunidades de melhorarias para a panificadora. Tais propostas tem investimentos baixos que resultaram em uma dinâmica entre ações propostas no programa, como a adoção da massa de prémistura que teve influência no aumento da produtividade, na diminuição do custo de produção e na redução de geração de resíduos.

Contudo, este estudo demonstra que mesmo para um empresa de pequeno porte, e que não é responsável por impactos ambienteis muito significativos, pode-se sim, adotar uma gestão que tenha como foco produzir de forma sustentável. 


\title{
Cleaner production program in the bakery sector of the city of Marabá-PA
}

\begin{abstract}
Industrial activities took decades to insert the environmental variable into their decisions, however recently has emerged sustainable initiatives in the productive process of large and small businesses. One of these sectors is the bakery industry, which despite being a small sector and does not generate hazardous waste, it does not prevent new sustainable production technologies being applied. One of these technologies is the Cleaner Production, which aims to optimize the productive process and prevent waste generation. This article aims to elaborate a cleaner production program in the bakery sector of the city of Marabá-PA. The research is inductive, exploratory and descriptive, in addition to being a case study characterized as qualitative. The methodology of Cleaner Production proposed by the National Center of Clean Technologies (CNTL) and the US National Protection Agency (EPA) was used. It was obtained that the main measure to be proposed was the use of the mass of premixture, together with the adoption of preview weigh and containers for dosages, in addition to the segregation and commercialization of the wastes of the Bread factory. Such proposals, have low investment and promote increased productivity, decrease in production costs and reducing waste generation.
\end{abstract}

KEYWORDS: Baking. Cleaner production. Waste. 


\section{REFERÊNCIAS}

ABIP (Associação Brasileira da Indústria de Panificação e Confeitaria). Performance do setor de panificação e confeitaria brasileiro em 2015. Brasília, Janeiro, 2016. Disponível em: <http://www.abip.org.br/site/sobre-o-setor2015/>. Acesso em: 23 out. 2016.

BERTÉLI, M. O.; BARCELLOS, P. F. P.; BORELLA, M. R. C. Mudança organizacional impulsionada pela produção mais limpa. Revista Gestão Industrial, Paraná, v. 09, n. 04: p. 849-867, 2013.

CNTL. Implementação de programas de produção mais limpa. Centro Nacional de Tecnologias Limpas SENAI-RS/UNIDO/INEP, Porto Alegre, 2003.

EPA (United States Environmental Protection Agency). Facility pollution prevention guide. Washington, maio, 1992. Disponível em: $<\mathrm{h}$ http://www.epa.ohio.gov/portals/41/p2/P2Facguide.pdf>. Acesso em: 30 out. 2016.

FERNANDES, L. J. M.; FREITAS, L. S. Análise do processo produtivo de uma panificadora na cidade de Campina Grande - Paraíba utilizando a ferramenta de P+L. Revista Espacios, Venezuela, v. 35, n. 05, 2014.

FINGER, L.; NETO, L. M. Análise das iniciativas de produção mais limpa promovidas laboratório de camarões marinhos da universidade federal de Santa Catarina. Revista Gestão Industrial, Paraná, v. 6, n. 4, 2010.

GERHARDT, T. E.; SILVEIRA, D. T.; (Organizadores). Métodos de pesquisa. Universidade Aberta do Brasil - UAB/UFRGS. Porto Alegre: Editora da UFRGS, 2009. 120 p.

GIL, A. C. Como elaborar projetos de pesquisa. 5. Ed. São Paulo: Atlas, 2010.

ISO, ABNT-NBR. 14001: Sistemas de gestão ambiental - Requisitos com orientações para uso. ABNT - Associação Brasileira de Normas Técnicas, Rio de Janeiro, RJ, 2015.

JUNIOR, F. D. P.; NETO, G. J. F.; RAMOS, M. P.; BANDEIRA, A. L. C.; SILVA, A. C. Produção mais limpa: um estudo de caso numa panificadora situada na região de natal - RN. XXXII ENCONTRO NACIONAL DE ENGENHARIA DE PRODUÇÃO. Anais eletrônicos. Bento Gonçalves, 2012. Disponível em: <http://www.abepro.org.br/biblioteca/enegep2012_TN_STO_165_961_20008.pd f>. Acesso em: 12 nov. 2016. 
MARCONI, M. A.; LAKATOS, E. M. Fundamentos de metodologia cientifica. 7. ed. São Paulo: Atlas, 2010.

MARCONI, M. A.; LAKATOS, E. M. Metodologia do trabalho cientifico: procedimentos básicos, pesquisa bibliográfica, projeto e relatório, publicações e trabalhos científicos. 7.ed. 6 reimpressão. - São Paulo: Atlas, 2011.

MILAN, G. S.; GRAZZIOTIN, D. Um estudo sobre a aplicação da Produção mais Limpa (P+ L). Gepros: Gestão da Produção, Operações e Sistemas, v. 7, n. 1, p. 127, 2012.

OLIVEIRA, J. M.; RODRIGUES, M.; ALVES, R. Estudo do impacto da inovação tecnológica no setor de panificação e confeitaria. ABIP/ITPC/SEBRAE de desenvolvimento do setor de panificação e confeitaria, 2012. 111 p.

PEREIRA, G. R.; SANT'ANNA, F. S. P. Uma análise da produção mais limpa no Brasil. Revista Brasileira de Ciências Ambientais, v. 24, p. 17-26, 2012.

SEGFAZ (Secretária Municipal de Gestão Fazendária). Departamento de cadastro mobiliário. Marabá - Pará, nov. 2016.

SENAI. Departamento Regional do Rio Grande do Sul. Produção mais Limpa em padarias e confeitarias/SENAI. Departamento Regional do Rio Grande do Sul. Porto Alegre: Centro Nacional de Tecnologias Limpas SENAI, 2007. 74 p.

SEVERINO, A. J. Metodologia do trabalho cientifico. 23. Ed. Revisada e atualizada. São Paulo: Cortez, 2007.

WERNER, E. M.; BACARJI, A. G.; HALL, R. J. Produção mais limpa: conceitos e definições metodológicas. Ingepro/ Inovação, Gestão e Produção, v. 03, n. 02. Fev. 2011. 
Recebido: 18 ago. 2017

Aprovado: 16 abr. 2018

DOI: 10.3895/gi.v14n2.6957

Como citar:

MIRANDA, L. B.; FRANCO, J. S.; LOUREIRO, G. E. Programa de produção mais limpa no setor de panificação da cidade de Marabá-PA. R. Gest. Industr., Ponta Grossa, v. 14, n. 2, p. 60-76, abr./jun. 2018.

Disponivel em: $<$ https://periodicos.utfpr.edu.br/rgi $>$. Acesso em: XXX

Correspondência:

Luciana Barbosa de Miranda

Rua Maranhão, 257, Laranjeiras, Marabá, Pará, Brasil.

Direito autoral: Este artigo está licenciado sob os termos da Licença Creative Commons-Atribuição 4.0 Internacional.

(c) (1) 